\title{
Os homens de cor invisíveis da imprensa negra paulistana: como a biografia de um intelectual negro nascido no século dezenove auxilia a repensar a historiografia do pós-abolição paulistano*
}

\author{
The invisible men of color in the São Paulo black press: how the biography of a black \\ intellectual born in the nineteenth century helps to rethink the historiography of post- \\ abolition in São Paulo
}

\author{
Lívia Maria Tiede \\ Doutoranda em História pela \\ Universidade Estadual de Campinas \\ liviatiede@gmail.com
}

\begin{abstract}
Resumo: O presente texto aborda aspectos históricos e historiográficos do pós-abolição a partir dos jornais da imprensa negra paulistana. Existentes desde pelo menos o final do século dezenove, os jornais negros de São Paulo foram considerados mais combativos a partir da segunda década do século vinte. A relevância bibliográfica atribuída a esse último período ofuscou a luta de ativistas dos decênios anteriores, cuja herança documental é menos acessível. O objetivo deste artigo é refletir acerca das possibilidades para se contornar o problema da ausência dos jornais negros paulistanos nos primeiros anos do século vinte. Desse modo, a investigação biográfica sobre intelectuais negros nascidos em fins do século dezenove - por vezes ainda sob o jugo da escravidão - e que foram atuantes sobretudo nos anos imediatamente posteriores a abolição faz compreender a experiência negra antirracista interligada entre ambos os períodos históricos.
\end{abstract}

Palavras-chave: Intelectuais negros, imprensa, biografia.

\begin{abstract}
This text covers historical and historiographical aspects of the postemancipation from the newspapers of the Black Press of São Paulo. The black publications appeared since at least the end of the nineteenth century, however, in this city they were considered more combative from the second decade of the twentieth century. The bibliographic relevance attributed to this last period overshadowed the struggle of activists from previous decades, whose documentary heritage is less accessible. The purpose of this article is to reflect on the possibilities to circumvent the problem the absence of the black press in the early years of the twentieth century. In this way, biographical research on black intellectuals born in the late nineteenth century (sometimes still under the yoke of slavery) who was mainly active in the years immediately after the abolition makes understanding the black experience against racism interconnected between both historical periods.
\end{abstract}

Keywords: Black intellectuals, press, biography.

\footnotetext{
* Essa pesquisa em nível de doutorado conta com o financiamento de uma bolsa de estudos da Fapesp (Fundação de Amparo à Pesquisa do Estado de São Paulo).
} 


\section{Os jornais negros paulistanos dos primórdios e a descoberta dos debates raciais entre os intelectuais da geração de Frederico Baptista de Souza}

Na última década, os estudos sobre o período após a abolição no Brasil deixaram de ser uma área adjacente das pesquisas sobre a escravidão. A pergunta mais ampla que orientou os pesquisadores a pensar a vida das pessoas recém egressas do cativeiro, ou livres de cor e libertos, depois do ano 1888, se problematizou e se expandiu. O mesmo pode ser dito sobre os estudos sobre imprensa negra, tanto no Brasil, quanto nas Américas (RIOS \& MATTOS, 2004: 170-198; PINTO, 2010; CHAPEAUX, 1936; GELER: 2010: 27-53).

Essa afirmação também condiz com os estudos sobre imprensa e associativismo negro em São Paulo. Na última década, muitos pesquisadores têm dedicado especial atenção as lides dos movimentos negros paulistanos e paulistas, em geral. Felizmente, esse cenário colabora para que se possa ter uma visão mais ampla das lutas e conquistas de pessoas negras durante o período posterior a 1888 (CARVALHO, 2009; TENÓRIO, 2010; CORTÊS, 2012; FORTES, \& MATTOS, 2015; PEREIRA, 2016).

Contudo, acerca dos anos imediatamente iniciais do século vinte, em especial durante as duas primeiras décadas, algumas premissas parecem solidificadas. Por exemplo, há pesquisas que reiteram que a imprensa negra paulistana das duas primeiras décadas era menos comprometida com o combate do racismo (DOMINGUES, 2007:103105). Outra afirmação é que de esses jornais e, portanto, seus articulistas, eram conservadores e subservientes a brancos poderosos, tendendo ao branqueamento, por se entenderem mais como paulistas do que como negros, assumindo, desse modo, uma postura assimilacionista (ALBERTO, 2011). Ainda, se assegura em pesquisas relativamente recentes que os jornais faziam uma exclusão das mulheres negras, entendendo-as como musas, e que não davam espaço para que elas se expusessem como participantes ativas do movimento (DOMINGUES, 2010:100-122; ALBERTO, 2011:3739).

A ideia de que os jornais negros posteriores a 1924 eram mais aguerridos racialmente que os impressos das décadas anteriores foi bastante repetida por um modelo de análise classificatório, que busca mostrar certa "evolução" do movimento negro, mas que se faz distante dos textos efetivamente políticos presentes nesses jornais dos primórdios (BASTIDE, 1952: 50-72; FERNANDES, 1965; FERRARA, 1986; 
DOMINGUES, 2007: 117). Entretanto, é com alegria que se pode perceber que muitos pesquisadores abandonaram tal argumento, mesmo entre aqueles que sustentam a base teórica sociológica da escola de São Paulo ${ }^{1}$ (CARDOSO, 2012). Isso se deu, entre outros aspectos, porque os jornais negros dos primórdios paulistanos, ou seja, aqueles publicados entre 1900 e 1915, não restaram para a posteridade, o que torna o trabalho do pesquisador mais difícil, afinal, é preciso coletar em outros documentos as informações que complementam a análise.

É importante ressaltar, contudo, que houve jornais negros paulistas no século dezenove que traziam debates políticos bastante explícitos, como demonstra o estudo Imprensa Negra no Brasil do século XIX, de Ana Flávia Magalhaes Pinto (2010). No terceiro capítulo deste livro que é uma referência indispensável para o estudo da imprensa negra no Brasil, a autora se detém especialmente a dois títulos paulistas, A Pátria e o Progresso. De acordo com a sua análise, A Pátria foi um periódico comprometido com a memória dos antepassados, "pais e avós e pares recém-libertos do escravismo" (PINTO, 2010: 21). Surgido em 1889, apresentava conteúdo republicano, e estimulava à luta contra o "preconceito de cor". O jornal Progresso, por sua vez, entendia que o governo republicano não afiançaria a plena cidadania aos egressos do cativeiro e aos seus descendentes. Desse modo, guiava os leitores à busca pelo benefício próprio, e sobretudo, demonstrava ceticismo para com a política hegemônica (PINTO, 2010: 21-23).

Como é possível apreender da pesquisa supracitada, o conjunto de jornais da imprensa negra paulista não se iniciou tardiamente na segunda década do século vinte, e nunca foi isento politicamente, ou mesmo uníssono. A despeito de não existir a herança material dos folhetins produzidos por intelectuais negros dos primórdios do 1900, a obra desses jornalistas paulistas deve ser avaliada sob a luz das produções do século dezenove, cujas folhas como A Pátria e o Progresso são elucidativas. A escolha de se observar os pasquins negros de ambos os períodos como um único corpus documental faz emergir um panorama analítico diferente acerca das lutas antirracistas, posto que não retifica uma suposta "interrupção" da produção intelectual negra paulistana, equivocadamente

\footnotetext{
${ }^{1}$ Paulino de Jesus Francisco Cardoso, no estudo A luta contra a apatia, faz um panorama clássico da história da população negra em São Paulo, pois recorta a pesquisa justamente para os anos em que restou a produção jornalística da imprensa negra, ou seja, entre 1915 e 1931. Ancorado fortemente nos estudos bibliográficos e nos periódicos da imprensa negra, o autor assume a periodização proposta pela escola de São Paulo, contudo, aponta para a necessidade de um esforço em se conectar a produção do século dezenove com o século XX. Cardoso dá o nome de "comunidade dos letrados" aos sujeitos desses jornais dos primórdios, como Frederico Baptista de Souza e Gastão Silva (CARDOSO, 2012).
} 
assumida sob a perspectiva da inexistência de periódicos nos primeiros anos do século vinte.

Houve uma intensa produção jornalística durante esses anos e, tal aspecto, pode ser certificado através das ações do movimento negro, e principalmente, por meio de relatos de memorialistas (CUTI, 1992) que se referem aos jornais extintos e da metalinguagem das folhas que sobraram e que citavam seus correligionários de anos anteriores (TIEDE, 2002). Outro aspecto essencial para se compreender o universo desses "homens de cor" é a percepção de que muitos intelectuais que foram atuantes nas décadas imediatamente posteriores a abolição, e que nasceram ainda no século dezenove sob o jugo da escravidão como, por exemplo, Frederico Baptista de Souza, continuaram a publicar e debater conceitos depois da década de 1920, junto à geração mais jovem do movimento negro. E por que isso é importante?

O estudo de práticas sociais e culturais da população negra de São Paulo entre os anos de 1915 e 1924, realizado por meio de jornais produzidos por intelectuais negros que tinham como público alvo a população negra - ou, na linguagem da época, eram "destinados à classe dos homens de cor"2 - mostra que essas pessoas faziam parte de uma rede social vinculada a clubes e associações dançantes, esportivas, humanitárias. Os redatores e colaboradores, em geral, pertenciam a esta rede de sociabilidade e noticiavam não somente os acontecimentos referentes à vida social ligada aos clubes (notícias de festas, quermesses, mexericos, falecimentos, aniversários, etc.), como também expunham ideias mais abrangentes sobre moral, costumes, política, educação, religião, trabalho, etc. (MACIEL, 1997; BUTLER, 1998; TIEDE, 2002).

Tais investigações priorizaram o mapeamento, tanto dos indivíduos que participavam da escrita dos jornais, quanto de suas práticas sociais, investigando principalmente seus valores e ideias através de seus laços comunitários e familiares e, consequentemente, suas estratégias de sobrevivência e melhoramento das condições de vida na sociedade paulistana pouco depois da abolição. Pesquisas feitas na série Jornais da Raça $\mathrm{Negra}^{3}$ - e em outros documentos complementares - construíram uma pequena

\footnotetext{
${ }^{2}$ Essa maneira de se auto referir é amplamente encontrada nos jornais; parece ser também uma maneira formal de se referir aos negros que participam de um determinado meio social.

${ }^{3}$ É importante ressaltar que esta terminologia Jornais da Raça Negra se trata do título aplicado pela seção de microfilmes da Biblioteca Mário de Andrade, de onde foram copiados os jornais microfilmados pelo Cecult (Centro de Pesquisa em História Social da Cultura) que estão disponíveis no Arquivo Edgard Leurentoh na Unicamp. Há também exemplares microfilmados no IEB - USP e no Centro de Documentação e Memória (Cedem) da Unesp. Atualmente é possível ter acesso a tais periódicos em diversas plataformas digitais como o Arquivo Público do Estado de São Paulo
} 
parcela da malha social tecida pela população negra paulistana no início do século. Tais trabalhos localizam a data do primeiro jornal da imprensa negra de São Paulo no século vinte, em $1915^{4}$. O recorte se finaliza em 1924, data de fundação do jornal Clarim d'Alvorada, pois esse é tido como o marco sociológico da intensificação do discurso político no movimento negro.

Ao examinar esses jornais, é possível compreender como se dava a interação entre as notícias e as formas de vida que se deixam ver nas entrelinhas, e verificar como as pessoas não-brancas se relacionavam com as práticas governamentais e, ainda, buscar através das propagandas de comércio, dos clubes dançantes e das discussões sobre diversos assuntos, como ocorria a articulação com vistas a burlar as práticas racistas do período.

Como estratégia metodológica, foram mapeadas as redes familiares, de amizade e de compadrio que envolviam os redatores e participantes desses jornais, técnica essa que se mostrou como uma estratégia importante, pois esta montagem possibilitou a verificação de laços interpessoais, que facilitavam o confronto e divulgação de ideias entre a sociabilidade negra. Por meio desse tipo de análise, é possível perceber como a participação ocorria no âmbito familiar, dentre os clubes e associações dançantes que muitas vezes foram entendidos como "diversão alienante", mas que, no entanto, possibilitavam intenso convívio ao criar e, concomitantemente, nutrir o círculo social das pessoas negras de São Paulo.

Um exemplo frutífero da tentativa de reconstruir essas redes de sociabilidade pode ser examinado por meio da articulação de Frederico Baptista de Souza, que foi um colaborador assíduo de diversas folhas, muitas vezes acumulando cargos entre a redação destas e diretorias em clubes e sociedades dos homens de cor. Porém, sua participação e de seus familiares e amigos - não se encerra nas atividades referentes à imprensa negra e clubes dançantes; ele foi atuante em diversos setores sociais. Cruzando as informações fornecidas pelos próprios jornais, vislumbravam-se as suas redes de laços e práticas de sociabilidade. Somadas e interligadas, essas trajetórias individuais permitiram remontar uma pequena rede social que pode dar continuidade a estudos posteriores sobre a população negra do período (MACIEL, 1997; BUTLER, 1998; TIEDE, 2002).

http://www.arquivoestado.sp.gov.br/memoria_imprensa/edicao_07/secao_imprensa_negra.php e também na USP http://biton.uspnet.usp.br/imprensanegra/

${ }^{4}$ Existe um exemplar da cidade de Campinas que data de 1904, chamado O Baluarte. 
Do ponto de vista metodológico, é importante ressaltar que essas pesquisas procuraram resgatar o que as pessoas, de pele escura, organizadas em torno de uma categoria de grupo consideravam sobre si próprias, de acordo com o conteúdo das fontes, depoimentos e comparação bibliográfica. Por meio da leitura dos jornais negros, é possível enxergar uma enorme preocupação com formas de elevação social, moral, pedagógica e literária entre outras ansiedades. Os jornais, que muitas vezes empregam a expressão "em prol da raça negra", dedicavam artigos bastante extensos sobre temas como educação, conduta, trabalho e preconceito racial.

Ao buscar compreender as redes de relações sociais, verifica-se a recorrência de vários artigos de um mesmo autor, principalmente quando a colaboração era frequente. Abílio Rodrigues, Joaquim Domingues e Frederico Baptista de Souza são alguns dos nomes que tomaram destaque. Ainda que alguns textos não fossem de colaboradores frequentes e, muitas vezes, apareciam apenas sob pseudônimos.

Alguns intelectuais de cor ficaram conhecidos por suas atividades jornalísticas e literárias. É o caso de Deocleciano Nascimento, redator-chefe de O Menelick, que frequentemente tinha suas poesias e sonetos publicados em diversos jornais. José Correia Leite se reporta a ele como "uma espécie de Cruz e Sousa no meio negro - um grande poeta" (CUTI, 1992: 19-57). O articulista A. Oliveira, que foi diretor do O Alfinete, também publicava artigos, principalmente no editorial deste jornal e, geralmente, seus temas eram raça, política, e condição moral do negro - ou melhor, do homem de cor. Mas, quem aparecia em todos os títulos, e em quase todos os números, era o Sr. Ico, como ficou carinhosamente conhecido Frederico Baptista de Souza. Sem conseguir identificá-lo com algum pseudônimo, nunca foi registrada uma poesia ou soneto de sua autoria. Seus textos do final da década de 1910 eram principalmente sobre a conduta moral do homem de cor ${ }^{5}$, exemplificados por meio de fatos que eventualmente aconteciam nas associações, os quais ele lamentava (BUTLER, 1998; TIEDE, 2002; ALBERTO, 2011). Nesse mesmo período, publicou regularmente memórias sobre participantes de associações dos homens de cor que já haviam falecido e costumava reforçar a ideia da necessidade de união entre as diferentes agremiações negras; com alguma frequência censurava determinadas atitudes da classe que não corroboravam a unidade dos elementos de cor (TIEDE, 2002: 22-27, 103).

\footnotetext{
${ }^{5}$ O ALFINETE, 1918; 1919.
} 
Evidentemente, ele não foi o único indivíduo a publicar nos jornais negros, mas estava entre os nomes mais pertinentes. Entre aqueles que escreviam utilizando pseudônimos, Matuto e Azuos foram as alcunhas mais constantes. Deve-se lembrar que uma grande quantidade de textos foi publicada sem assinatura, anônimos, que provavelmente eram escritos pela própria redação dos jornais. Há, também, além dos escritores, menções as pessoas do círculo social que não escreviam na imprensa negra. Isso porque os jornais eram atentos a vivência cotidiana dos indivíduos e do coletivo, narrando os encontros e desventuras do ambiente em que estavam inseridos, especialmente através das seções sociais e de críticas.

É realmente notável a dedicação ao relato de quem fez o que, onde e como. O problema é que essas notas sociais, as fofocas, são muitas vezes opacas ao leitor atual: era raro que fosse noticiado o nome e sobrenome do alvo da crítica. É por esse motivo que fica mais fácil ao pesquisador seguir os passos daqueles que mais se destacavam. Se, por exemplo, em alguma fofoca surgisse o nome Frederico, mesmo sem sobrenome, pelas características demonstradas em outras linhas dos jornais, seria possível supor se condizia com Sr. Ico ou não. Mas, é improvável descobrir quem era a "Carolina do Chuveiro de Prata (agremiação)" pela indicação de que seus dentes eram alvos (TIEDE, 2002: 23).

Além da afamada seção de fofocas, existiram outras seções que também apareciam regularmente. É o caso, por exemplo, daquelas que traziam notícias sobre as atividades das associações por meio de notas sobre os eleitos para ocuparem os cargos de diretoria, a prestação de contas, as atividades planejadas para períodos futuros, os sócios eliminados por falta de pagamento, os admitidos, eventos importantes, novas regras e mudança de sede, entre outros exemplos menos corriqueiros.

Era comum que saísse ao menos um soneto ou poesia, de autor desconhecido, pelo menos para quem não era homem de cor. Algumas mulheres publicavam também, principalmente textos românticos. O jornal O Menelick, por exemplo, comentava em janeiro de 1916, que seu próximo número seria dedicado aos textos femininos ${ }^{6}$, porém, esse exemplar não está entre aqueles que foram conservados na série Jornais da Raça Negra. Desse modo, pode-se pensar: será que os jornais realmente excluíam e as mulheres (ALBERTO, 2011: 39-40), ou será que a inexistência do periódico que refutaria essa ideia é que leva os pesquisadores a acreditar que eles assim procediam?

${ }^{6}$ O MENELICK, 1916: 3. 
Sem dúvida, é inegável a importância da questão do comportamento e da respeitabilidade recorrentes nas folhas primevas do pós-abolição paulista. A pergunta que pode auxiliar a se repensar as investigações científicas é, portanto, se a ideia de respeitabilidade esteve presente em todas as folhas do início do século, ou, ao contrário, se fora refutada por outros títulos para os quais não existe mais o acesso.

Em muitos exemplares, pode-se observar que havia preocupações que apareciam reiteradamente na imprensa negra paulista anterior a 1924. Por meio de cruzamento de artigos de títulos distintos pode-se verificar dois aspectos singulares. O primeiro de que, como já demonstrou Pinto (PINTO, 2010: 21), havia jornais divergentes entre si. Mesmo que não haja coleções completas desses títulos, é possível encontrar e narrar alguns exemplos que comprovam essa afirmação. E o segundo, a constatação de que esses intelectuais, anteriores a geração de 1924, estavam totalmente cientes dos debates internacionais sobre a "questão da raça negra" - o que por si só já confirma que esses periódicos eram tudo, menos pouco comprometidos com os debates de raça e racismo (TIEDE, 2002).

É o que se pode deduzir de um artigo publicado em 1923 no jornal $O$ Kosmos $^{7}$. Mesmo que o texto não seja do princípio do século vinte, o periódico era órgão oficial do Grêmio Dramático e Recreativo Kosmos, fundado em 1908 por ninguém menos que Frederico Baptista de Souza. O texto é de autoria de Abílio Rodrigues, um dos representantes do jornal e amigo Frederico que, inclusive, em uma ocasião de conflito dentro do clube chegou a enviar um ofício ao Grêmio Kosmos, pedindo a readmissão de Frederico Baptista de Souza no quadro de sócios.

No artigo, Abílio Rodrigues expõe que o Dr. Robert Abbott, reconhecido líder negro norte americano e fundador do jornal norte-americano Chicago Defender, em visita ao Brasil, havia feito uma conferência, posteriormente relatada por José do Patrocínio Filho no jornal carioca A Pátria, no dia 14 de março. Na palestra, o "líder da raça negra em Chicago" Abbott teria afirmado que o Brasil seria um país de igualdade racial, ideia que foi absolutamente refutada por Abílio Rodrigues:

O Dr. Abbott acredita nos princípios estabelecidos pela igualdade humana, certamente pela ilusão que teve ao deparar à primeira vista, com o contato entre o preto e o branco em todos os atos sociais, mas só na aparência, porque

\footnotetext{
${ }^{7}$ O KOSMOS, (1923): 1-2.
} 
particularmente o preto daqui, não passa do que deve ser e chegar a ser. Os dados colhidos pelo Dr. Abbott produzirão aos pretos de Norte América um sinal de evidente alegria, mas para o Brasil será a verdadeira tristeza: conservando-os nessa ilusão de igualdade, em que perdura o desprezo e todos os feitos apontados como inúteis e tolerados (O KOSMOS, 1923: 1)

Desse modo, podemos observar que um dos intelectuais do jornal $O$ Kosmos, a ver Abílio Rodrigues, não apenas estava ciente das ideias de Dr. Abbott sobre a suposta igualdade racial no Brasil, como de fato, as considerava negativas para as necessidades sociais dos negros brasileiros. Para dar ênfase a seu argumento, Abílio Rodrigues narrou, então, uma situação de evidente racismo sofrida pelo próprio Dr. Abbott em solo brasileiro:

[...] em um de nossos hotéis, O Palace Hotel, de volta de um passeio, [Dr. Robert Abbott] foi convidado pelo proprietário não mais continuar como hóspede, porque o quarto já tinha sido tomado por outro. Por que? Devido achar-se hospedado no mesmo hotel, alguns norte-americanos brancos, que impuseram o dono despedir o hóspede preto. [...] é essa igualdade apontada como padrão de verdadeira democracia brasileira? Ilusão... perfeita ilusão. (O KOSMOS, 1923: 2.)

Em 1992 foi publicada a obra African-American reflections on Brazil's racial Paradise, em que há um texto de autoria de Robert Abbott intitulado "My trip Through South America". Nele, o fundador do Chicago Defender, também narra essa mesma discriminação sofrida por ele e seu grupo no Palace Hotel:

Nós chegamos a São Paulo no final da tarde. Fomos ao Palace Hotel, onde nos acomodamos, mas, tão irritante quanto possa parecer, durante a noite nós fomos informados pelo proprietário de que um número razoável de turistas americanos, hóspedes no hotel, reclamaram de nossa presença, e pediram que abandonássemos nossa suíte. [tradução da autora] (HELLWIG, 1992:64).

Nesse mesmo texto, Robert Abbott, contudo, reafirma as suas suposições sobre a suposta igualdade racial brasileira, chamada de "absoluta harmonia social", que levaram Abílio Rodrigues a indignação: 
Mas, a despeito da grande variedade e grandes diferenças de tipos fisionômicos e de posicionamentos, há um estado de absoluta harmonia social. Negros e brancos casam-se entre si, sem provocar a menor censura social. Em conjunto, a tendência parece encorajar casamentos entre vários tipos diferentes, como brancos e africanos - o ideal de ser uma perfeita política de estado através da homogeneidade de sangue. (...) Um futuro brilhante é assegurado a Raça Negra no Brasil, e sem a situação de adversidades no país as pessoas tornarão a beleza física, inteligência, vigor e instinto progressivo sem igual em nenhuma parte do mundo... [tradução da autora] (HELLWIG, 1992: 65-66).

A comparação demonstrada entre a vinda do militante negro a São Paulo e a notícia do jornal $O$ Kosmos procura dar ênfase a ideia de que os homens de cor brasileiros, militantes desde o início do século vinte, estavam bastante interessados em discutir preconceito racial no Brasil e totalmente conscientes dos debates globais acerca das questões de raça e racismo. Atualmente, é sabido que os diálogos entre o movimento negro brasileiro e norte-americano não se restringem a esse episódio (DOMINGUES, 2006; GOMES, 2007; RIBEIRO, 2010).

Há um universo negro paulista e paulistano de princípios do século vinte que ainda está semicerrado e que precisa ser desvendado, a despeito da pequena existência da herança material dos jornais desse período. O grupo que circundava essa produção jornalística tinha conceitos políticos e sociais muito mais complexos do que aquilo que a pouca presença material dos jornais tende a desvelar.

Felizmente, há exceções que indicam uma forma não de contornar as lacunas, mas ao contrário, de preenchê-las. Especialmente as investigações que se esmeram em procurar, cruzar e analisar outros documentos e fontes, para além dos jornais, têm se mostrado frutíferas e, possibilitam que, aos poucos, seja possível edificar, tijolo por tijolo, um panorama mais condizente com o universo do imediato pós-abolição, em São Paulo. Fontes cartoriais, documentos eleitorais, produção literária, documentação policial, produção de irmandades e confrarias, jornais da imprensa hegemônica, processos, documentação trabalhista - em tudo isso há os nomes daqueles que viveram as folhas negras do início do século. O ponto de partida pode ser, de fato, os poucos números dos jornais negros, mas o de chegada precisa ser mais amplo do algumas conclusões cristalizadas pela bibliografia há mais de 50 anos atrás (BUTLER, 1998; AMÂNCIO, 2013; PINTO, 2014; SILVA, 2017). 
Desse modo, a questão da respeitabilidade dos homens de cor do início do século precisa ser vista sob um horizonte global. A conduta moral também era assunto do movimento negro internacional no início do século vinte, em especial o norte-americano, e ainda que haja muitas críticas a esse modelo de ativismo, hoje, pode-se afirmar que a seria impossível pensar que os líderes negros paulistanos não estivessem absolutamente atentos a essa discussão, posicionando-se quanto a esse aspecto (TUTTLE, 1970; BUTLER 1998).

Feita essa introdução e contextualização sobre as possibilidades analíticas acerca dos intelectuais negros paulistas dos primórdios do século vinte, apresentaremos alguns resultados da pesquisa que vem sendo realizada sobre a biografia de Frederico Baptista de Souza. Como tentamos mostrar, pesquisas anteriores auxiliaram o caminho para que o nome e ações de Frederico emergissem do silêncio dos tempos. Contudo, apenas os jornais negros seriam insuficientes para reconstruir sua trajetória de vida e militância. Edificar a colcha de retalhos para reconstruir seus passos, no entanto, possibilita duas coisas muito importantes: a) perceber por meio de sua vida como militantes negros circulavam nos mais diversos espaços de atuação política, e ampliar as possibilidades de conexões históricas entre as atuações dos sujeitos e demais setores sociais; b) entrever atrelamentos e conflitos que coexistiram no movimento negro para além do que já foi consolidado pela bibliografia sobre o tema.

\section{A trajetória de Frederico Baptista de Souza: um militante negro paulistano entre 1900 e 1932}

Invisibilidade, deixe-me explicar, dá um sentido um pouco diferente do tempo, você nunca está completamente na batida. Às vezes você está à frente e às vezes atrás. Em vez do fluxo rápido e imperceptível do tempo, você está ciente de seus nós, aqueles pontos onde o tempo está parado ou de que salta adiante. E você escorrega nas pausas e olha em volta. ${ }^{8}$ (ELLISON, 1952: 8)

\footnotetext{
${ }^{8}$ Esta versão é uma tradução livre da autora, feita do original em inglês “The invisible man”. Contudo, há uma versão do livro em português realizada pela editora José Olympio, cuja primeira edição é de 6 de dezembro de 2013, e foi intitulada "Homem invisível".
} 
A trajetória de vida e militância de Frederico Baptista de Souza pode ser investigada por meio dos jornais negros, em notas da grande imprensa paulista, em atas do funcionalismo público do Estado, em documentos da Faculdade de Direito e em documentos cartoriais. Nascido quatro anos depois da Lei do Rio Branco, em 26 de outubro de 1875, na cidade de Taubaté, era filho de uma cativa. A transcrição do registro paroquial de seu nascimento informa que ele era "filho de Silveria, escrava de Mariano Vieira da Cruz" e que tinha por padrinhos "Manuel Vaz de Toledo, escrivão do asilo de órfãos, e dona Umbelina Maria Marques" $"$.

Em 20 de julho de 1895, pouco antes de completar vinte anos, ele se casou com Luiza de Moura (Baptista) com quem viveu por 65 anos. Juntos, eles deram origem a uma família numerosa, cujos filhos, netos e sobrinhos foram atuantes no movimento negro e associativo. Dois anos após o matrimônio, nasceu José Martinho de Moura Baptista e, logo depois disso, a família Moura-Baptista se transferiu de Taubaté para a cidade de São Paulo.

Alguns anos antes da mudança para a capital, todavia, em outubro de 1896, Frederico assinou uma nota do jornal O Correio Paulistano em que representava a Associação Artística e Literária de Taubaté como secretário, função que veio a desempenhar em outras organizações ao longo de toda a sua vida.

Foi exatamente em 1900, aos 25 anos, que Frederico iniciou a sua longa carreira na Faculdade de Direito do Largo São Francisco ${ }^{10}$. Primeiro exerceu a função de guarda, e, progressivamente, ocupou outros cargos até chegar à posição de $1{ }^{\circ}$-Secretário, posto mais alto que alcançou durante os 43 anos em que lá permaneceu". O "Boletim de Merecimento" do funcionário afiança que, durante todo o tempo de serviço, ele teve apenas duas faltas, ambas justificadas. No documento há também uma anotação feita à mão: "É um funcionário de inteira confiança, caráter e idoneidade" 12 .

Fiel às suas causas foi incansável militante do movimento associativista. Participou de irmandades religiosas, entre elas: a Irmandade de Nossa Senhora do Rosário dos Homens Pretos e da Confraria Nossa Senhora dos Remédios ${ }^{13}$, onde ele e a esposa

\footnotetext{
9 UNIVERSIDADE DE SÃO PAULO (1942). Pasta do Funcionário Frederico Baptista de Souza. Transcrição do Registro Paroquial (Seção de Arquivo e Museu) - 1942.

${ }^{10}$ UNIVERSIDADE DE SÃO PAULO (1942). Pasta do Funcionário Frederico Baptista de Souza. (Seção de Arquivo e Museu) - 1942. São Paulo.

${ }^{11}$ UNIVERSIDADE DE SÃO PAULO (1942). Pasta do Funcionário Frederico Baptista de Souza. Mapa do tempo de serviço. (Seção de Arquivo e Museu) - 1942.

12 UNIVERSIDADE DE SÃO PAULO (1942). Pasta do Funcionário Frederico Baptista de Souza. Boletim de Merecimento (Seção de Arquivo e Museu) - 1942. São Paulo.

${ }^{13}$ O CORREIO PAULISTANO, 31/10/ 1919.
} 
foram atuantes já na década de $1910^{14}$, e vale lembrar que ambas as irmandades mantiveram um profundo vínculo (PINTO, 2014: 241). A Confraria Nossa Senhora dos Remédios foi um importante reduto abolicionista durante o século dezenove que contou com nomes de destaque como o de Antônio Bento (QUINTÃO, 2002). E a Irmandade Nossa Senhora do Rosário dos homens pretos fomentou indivíduos que vieram a formar a Liga dos Homens de Cor (PINTO, 2014: 271). Essas relações não são fortuitas, afinal outrora, no século XVIII, as irmandades proporcionaram um espaço de "experiência" da vida coletiva e associativista quando assumiram certa proteção às práticas culturais, trazidas durante a diáspora africana, como o catolicismo de Angola. No entanto, ao longo do século dezenove e principalmente no século vinte, as irmandades e igrejas assumidamente negras passaram a ser alvo de crescente acossamento, sobretudo por meio de desapropriação de terrenos e proibição desses cultos ancestrais (ABREU, 2000; REGINALDO, 2011; PINTO, 2014).

A dissertação de Liane Muller evidencia como a Irmandade Nossa Senhora do Rosário dos Homens Pretos da cidade de Porto Alegre, que durante o século dezenove foi voltada para a compra de cartas de alforria e instrução dos irmãos negros, deu origem a diversas associações recreativas e beneficentes de caráter racial depois da extinção do cativeiro e, especialmente, durante o século vinte (MULLER, 2013). A investigação de Muller ajuda pensar que a dupla pertença a Frederico e sua família, às associações leigas e, simultaneamente, às irmandades religiosas e pode apontar, ainda, que por meio de fragmentos, para afinidades entre os empreendimentos abolicionistas e para as iniciativas que visavam a conquista da cidadania no pós-abolição.

É bastante significativo que a trajetória combatente de Frederico tenha potencial de descortinar intercessões entre o movimento negro e outras formas de associativismo. Tal imbricação entre ativismos distintos tem sido averiguada por demais pesquisas historiográficas, já que acarretam sofisticação e profundidade à análise e podem desvendar um universo mais rico acerca das relações entre esferas múltiplas da sociedade (LONER, 1999; MAC CORD, 2012; PINTO, 2014) ${ }^{15}$.

\footnotetext{
${ }^{14}$ O ESTADO DE SÃO PAULO, 23/07/1915, 31/10/1919.

15 A produção bibliográfica do Sul do Brasil chama a atenção para as articulações regionais e os vínculos com as entidades de classe. O trabalho de Beatriz Loner explora a inserção dos escravos negros em associações mutualistas, e entidades profissionais, que não necessariamente explicitavam a identidade étnica, mas cujo amparo e apoio mútuo foram fundamentais na experiência do pós-abolição nas cidades de Pelotas e Rio Grande (RS) (LONER, 1999).
} 
Desse modo, é também instigante constatar que Frederico participou de dezenas de outras associações. A título de exemplo, ele foi secretário na Sociedade Beneficente dos Empregados Públicos ${ }^{16}$, de ajuda mútua e caráter trabalhista. Esteve entre os fundadores do Partido Democrático da Penha e foi diretor presidente da Associação Beneficente e Democrática do mesmo distrito.

Junto a outros militantes que deram origem aos jornais negros (DOMINGUES, 2007), Frederico atuou em funções mais modestas como a de relator ${ }^{17}$, e nos cargos mais prestigiosos, como de presidente e diretor. Como dito, nas folhas negras ele publicou artigos de sua lavra ${ }^{18}$, mas, sobretudo, se dedicou a organização prática do ativismo, pois ele foi secretário em muitas e diversificadas frentes de batalha. E por que tantas investidas?

O seu interesse pela militância política pode ter surgido pelo exemplo hercúleo de homens negros literatos e abolicionistas. José do Patrocínio, Luiz Gama e Ferreira de Menezes, por exemplo, publicaram artigos em periódicos de grande circulação tanto na capital como no interior do Estado, notadamente, durante o debate emancipacionista em fins do século dezenove, anos em que, devido à idade, Frederico conquistava o seu amadurecimento intelectual. É conveniente ressaltar que tais homens negros, formadores de opinião, estudaram ou tiveram algum tipo de passagem pela Faculdade de Direito de São Paulo. Assim, se torna legítimo ao menos especular se Frederico, bem como outros (não raros) funcionários negros do estabelecimento, tenha sido amparado por algum dos ex-estudantes abolicionistas para adentrar no funcionalismo público (PINTO, 2014: 248).

Deve se levar em consideração que as contratações não ocorriam através de aprovações em concursos, mas sim por meio de indicação formal. Haja vista o inegável recrudescimento do racismo durante o pós-abolição, essa especulação investigativa não é um aspecto irrelevante. $\mathrm{O}$ cargo na instituição pública também acarretava em prestígio, já que incidia em uma carreira sólida com estabilidade empregatícia e, portanto, concedia credibilidade financeira ${ }^{19}$ (AZEVEDO, 1996). Ser funcionário público da Faculdade de Direito fez com que Frederico tenha sido noticiado por várias vezes, de forma especial,

\footnotetext{
16 O ESTADO DE SÃO PAULO, 27/01/1906. "Movimento Associativo Sociedade Beneficente dos Empregados Públicos".

${ }^{17}$ Relator era a função de acompanhar os eventos sociais para posteriormente os narrar nos periódicos.

18 O ALFINETE, 09/03/1919, Frederico Baptista de Souza, "Ilusão":1.

19 Thales de Azevedo analisa uma série de aspectos das chamadas elites de cor na cidade de Salvador, por meio de entrevistas com pessoas que ascenderam socialmente. Em "Burocracia" Azevedo explicita que nas repartições públicas "os funcionários públicos eram admitidos por influência de políticos ou membros influentes da própria administração pública” AZEVEDO, 1996.
} 
nos periódicos da imprensa negra como referência de comportamento e exemplo a ser seguido. Ele próprio, também, fez uso da narrativa de sua história pessoal para incentivar os mais jovens a buscarem virtuosismo no trabalho, na família e no caráter. Como foi fundador e dirigente em mais de uma agremiação "de cor" na capital, compreende-se que seu ativismo teve um significado mais amplo para o meio negro do que apenas subjetivo ou íntimo. E como isso começou?

O início de sua militância no associativismo negro pode ter se principiado em 1904, quando ele foi eleito relator de um clube negro chamado 28 de Setembro, como foi publicado em uma nota sucinta do jornal O Estado de São Paulo ${ }^{20}$. A data que dá nome ao clube refere-se aos dois códigos imperiais anteriores a abolição, a Lei do Ventre Livre e a Lei dos Sexagenários, e designou várias das sociedades de cunho racial brasileiras. Clube Beneficente Cultural e Recreativo 28 de Setembro, por exemplo, é o nome da primeira agremiação "de cor" do Estado de São Paulo, fundada em 1897, em Jundiaí (SILVA, UNGARETTI \& CAPORRINO, 2013).

De acordo com os apontamentos sobre o movimento negro brasileiro, realizados por Petrônio Domingues, as associações negras no período republicano nasceram para fazer frente à marginalização sofrida por ex-escravos e seus descendentes. No artigo, Domingues também enfatiza a primazia da associação nascida ainda durante o século dezenove, e dá destaque a outras duas organizações: "Em São Paulo, a agremiação negra mais antiga desse período foi o Clube 28 de Setembro, constituído em 1897. As maiores delas foram o Grupo Dramático e Recreativo Kosmos e o Centro Cívico Palmares, fundados em 1908 e 1926, respectivamente" (DOMINGUES, 2007).

A sociedade veterana 28 de Setembro tinha importância estratégica, pois congregava pessoas vindas de lugares diferentes em sua sede e de outras cidades, nas quais promovia festas, bailes e piqueniques. É provável, portanto, que tenha sido nessa associação que Frederico tenha desempenhado a função de relator.

O Grêmio Dramático e Recreativo Kosmos foi fundado por Frederico, sua família, e outros ativistas em 15 de novembro de 1908, de acordo com as reiteradas memórias publicadas na imprensa negra (TIEDE, 2002). Grupos como esses, coordenavam eventos sociais notadamente orientados para negros em contexto de grande discriminação (AZEVEDO, 1996). Os bailes de pessoas negras tinham que possuir um registro especial para funcionar, caso contrário, o grupo era passível de multas (DOMINGUES, 2000). As

\footnotetext{
${ }^{20}$ O ESTADO DE SÃO PAULO, 22/01/1904.
} 
associações enfatizavam a programação orientada ao lazer, mas o Grêmio Kosmos nasceu sob a inspiração de integrar os bailes dançantes a propostas de ações beneficentes e atividades culturais e educacionais, ou seja, com a finalidade de expandir os horizontes de organização e atuação. No entanto, mesmo tendo sido uma agremiação potente, ainda não foi realizada pesquisa dedicada a entender essa sociedade e a atuação da família Baptista, aspecto que essa pesquisa em nível de doutorado vem desenvolvendo por meio da trajetória de Sr. Ico.

Como explicitado na primeira parte desse artigo, a maioria das teses que estudaram o movimento negro e sua imprensa na época posterior a Lei Áurea, dedicou especial atenção a produção realizada depois de 1924, a partir da publicação do jornal Clarim d'Alvorada. A ideia de que os jornais anteriores a essa data eram "apolíticos" foi, muitas vezes, aceita sem contestação (FERRARA, 1986; TIEDE, 2002). Especialmente, porque foi referendada pelo militante José Correia Leite, fundador do jornal $O$ Clarim, junto de Jaime Aguiar. Frederico era 25 anos mais velho que o jovem Leite, que decênios depois teria suas memórias publicadas, em 1992. Nessa obra, o famoso militante negro reconheceu a importância do Grêmio Kosmos que, em suas palavras, era diferente dos outros clubes da capital, porque aglutinava atividades beneficentes, literárias e artísticas, e não apenas de recreação (CUTI, 1992).

De acordo com a narrativa de José Correia Leite, as disputas por liderança no meio negro foram protagonizadas por ele, cujo ideário político tendia à esquerda, e Arlindo Veiga dos Santos, simpático ao integralismo de Plínio Salgado. Dr. Arlindo veio a ser o principal fundador da Frente Negra Brasileira, em setembro de $1931^{21}$. Não obstante, antes da fundação da Frente, houve uma tentativa ainda pouco investigada de união entre os dois líderes antagônicos e demais integrantes do movimento negro (BARBOSA, 1998; FERREIRA, 2005; DOMINGUES, 2006; RIBEIRO, 2010).

No dia treze de maio de 1931, a folha Clarim d'Alvorada anunciou que militantes negros se juntavam para criar uma "associação única", a Sociedade Cooperadora Clarim d'Alvorada. Os objetivos eram: "capitalizar a situação econômica" do jornal e torná-lo uma publicação majoritária dos homens negros; superar as divergências políticas; e conglomerar a "raça em uma frente única". O periódico assumiria uma nova orientação,

\footnotetext{
${ }^{21}$ Importantes militantes do movimento negro, em torno de 20 anos mais jovens que Frederico Baptista de Souza. José Correia Leite foi um dos fundadores do jornal Clarim d'Alvorada em 1924. Arlindo Veiga dos Santos foi a principal liderança da Frente Negra Brasileira, fundada em 1931. (FRANCISCO, 2010; BARBOSA, 1998; DOMINGUES, 2006: 517-536).
} 
e a presidência da Sociedade Cooperadora foi atribuída ao reconhecido veterano das associações, Sr. Ico, que contava com 57 anos de idade e acumulava mais de 30 anos de experiência em favor da "classe dos homens de cor".

A sociedade acabou em 1932, entre muitas brigas, como a notória tentativa dos irmãos Veiga dos Santos de empastelar a tipografia que funcionava na casa de José Correia Leite. Por sua vez, para se contrapor à cooperadora, Leite criou um jornal chamado Chibata e nele intimou os jornalistas do Clarim a fazerem greve contra o Gandhi da Frente. O artigo afirma que o conhecido "secretário" estava condicionando as publicações do Clarim aos temas determinados pelos irmãos Veiga dos Santos (BUTLER, 1998) ${ }^{22}$. Parte da imprensa hegemônica da década de 1930 acusava Mahatma Gandhi de fazer o jogo político dos britânicos contra os indianos ${ }^{23}$. A alcunha dada a Frederico não foi, portanto, isenta de ironia. E o até então diplomático mediador, passou a ser entendido como cúmplice dos dirigentes integralistas da Frente Negra Brasileira. Ele, que não foi sócio da Frente, respondeu às acusações no jornal o Clarim, que estava sob sua administração ${ }^{24}$.

Mas, depois da briga, o veterano parece ter se afastado do movimento negro. Possivelmente, porque a partir da década de 1940 o Sr. Ico teve inúmeros empecilhos para receber os rendimentos de sua aposentadoria como funcionário público. A última notícia encontrada sobre o militante, infelizmente, não foi publicada em nenhuma folha da imprensa negra. Em 27 de julho de 1960, a missa de sétimo dia de seu falecimento foi realizada na matriz da igreja da Penha. Um ano depois de sua morte, sua aposentadoria foi, finalmente, deferida.

\section{Conclusão}

É necessário notar que Frederico foi de uma geração do movimento negro que ainda tinha nascido sob as leis da escravidão. Carregava o fardo (ou a missão) de se erigir, negro que era, em um mundo identificado como moderno, livre e republicano, ainda que gestado durante o império escravista. Sua identidade se constituiu desse modo, de forma diferente de célebres militantes da geração posterior, como José Correia Leite, ou Arlindo

\footnotetext{
${ }^{22}$ Kim Butler apresenta as disputas envolvendo os senhores José Correia Leite e os irmãos Arlindo Veiga dos Santos. Ela quem primeiro infere que no centro desse "front" houve um Gandhi. Ela aponta Frederico como referência icônica entre a briga que colocava integralistas e comunistas em lados diversos do movimento negro da década de 1930 (BUTLER, 1998).

${ }^{23}$ FOLHA DA MANHÃ, 24/01/1930. "Mahatma Gandhi":9.

${ }^{24}$ CLARIM, 13/05/1932. Frederico Baptista de Souza, "Peço a palavra".
} 
Veiga dos Santos, já que Frederico Baptista de Souza viveu e viu a servidão com seus próprios olhos até os treze anos de idade ${ }^{25}$.

Sobre o associativismo negro e imprensa negra, é inegável o pioneirismo da obra "A integração do negro na sociedade de classes", de Florestan Fernandes, especialmente o segundo volume, que trata dos movimentos sociais no "meio negro" (FERNANDES, 1965). Membro da Associação Cultural do Negro (SILVA, 2012: 227-273), Fernandes teve amplo acesso aos depoimentos de José Correia Leite, dentre outros militantes antagônicos, quase quatro décadas antes da publicação do livro das suas memórias (CUTI, 1992). A sua interpretação sobre o surgimento da imprensa negra, bem como, sobre os clubes negros é fortemente alicerçada nas ideias do fundador do jornal O Clarim. Segundo suas palavras, teria sido apenas após a I Guerra Mundial que "ergueu-se o "protesto negro', como 'clarim da alvorada' [com letra minúscula], inscrevendo nos fastos históricos da cidade os pródromos da Segunda Abolição". Sobre a fase anterior, em que a participação de Frederico e de sua família foram preponderantes, o autor chamou de "agitação larval", que se apresentava: "correspondendo ansiosamente às expectativas assimilacionistas da sociedade inclusiva" (FERNANDES, 1965: 5).

Talvez, por conta da proximidade que tinha com os ativistas durante a década de 1940, Fernandes narrou de forma extremamente sutil os "conflitos intestinos do 'meio negro"” (FERNANDES, 1965: 47), por vezes fazendo certa conciliação póstuma entre líderes divergentes, como José Correia Leite e Arlindo Veiga dos Santos. O apaziguamento realizado por Fernandes poderia lhe parecer crucial no momento em que escrevia: possibilitaria nova arregimentação frente ao esfacelamento causado pelo Estado Novo, que havia colocado na ilegalidade todas as organizações sociais. Não obstante, é pertinente que haja outra leitura de tais disputas, à luz de uma abordagem que faça emergir os aspectos eclipsados para além da polarização entre um e outro líder.

Afinal, essa lógica de interpretação do passado busca valorizar as ações dos grupos posteriores a 1924, mas por sua vez, subestima as coletividades surgidas nas décadas anteriores. Tal explicação sobre a militância negra dos primeiros anos de 1900 acabou se cristalizando na bibliografia. Apesar de cunhar essa interpretação que valoriza um período em detrimento de outro, Fernandes faz uma ressalva, postulada também por José Correia

\footnotetext{
${ }^{25}$ José Correia Leite foi fundador do jornal O Clarim, junto de Jaime Aguiar. Em 1992 suas memórias publicadas foram publicadas. De acordo com a narrativa de José Correia Leite, as disputas por liderança no meio negro foram protagonizadas por ele, cujo ideário político tendia à esquerda, e Arlindo Veiga dos Santos, simpático ao integralismo de Plínio Salgado. Dr. Arlindo veio a ser o principal fundador da Frente Negra Brasileira, em setembro de 1931 (CUTI, 1992).
} 
Leite: “constitui exceção, nessa época, o Grêmio Recreativo Kosmos, que realizou seu programa educativo: teve um grupo dramático, e um jornal que publicava notícias sociais e ensaios literários"26 (FERNANDES, 1965: 31), ainda que mesmo assim, não tenha havido pesquisa sistemática dedicada ao Grêmio fundado por Frederico.

Se o Grêmio Kosmos foi exceção aos programas exclusivamente recreativos, por que suas atividades pouco constam da história do associativismo negro? A resposta pode estar na escassez de fontes, mas também, repousa na leitura que as escolas sociológicas tiveram condições de fazer, quando as perguntas não apontavam para as conexões entre movimento negro do século vinte e as lutas por liberdade de fins século dezenove (PINTO, 2014). Esse tipo de explicação fez parecer que depois da abolição teria ocorrido um lapso na luta antirracista e na produção intelectual das pessoas negras até meados da década de 1920, o que não ocorreu.

Os estudos de história social, onde a pesquisa que desenvolvo se situa, ao contrário das primeiras investigações, comprovam a importância dos pasquins primevos no que concerne às lutas e as reivindicações da população negra. Em fins da década de noventa, a historiadora Kim Butler fez uma leitura perspicaz da imprensa negra paulista, demonstrando que, além de os jornais dos primórdios não serem restritivos quanto às lides antirracistas, foram, sobretudo, os propulsores do movimento negro associativista paulista (BUTLER, 1998, ANDREWS, 1998, AMÂNCIO 2013, PINTO, 2010 e 2014).

Segundo a autora, é muito plausível dizer que os jornais da imprensa negra nasceram dentro dos clubes negros, ao menos para o século vinte. Ela demonstra que a "autodeterminação" criou as bases para a organização de clubes, comitês, grupos de teatro e bandas de música e, ao contrário do que afirmam as análises econômicas, o desejo de ascensão social não afastou a "elite negra" de suas origens humildes, mas sim foi crucial para gerar a demonstração de simpatia entre os negros que viviam em situações econômicas distintas. Para Butler, a primeira fase dos jornais negros contribuiu para a consolidação das noções de identidade da população afro-paulista, que ao se posicionar ao lado do nacionalismo, em voga na época, reafirmava a importância das contribuições históricas da população negra no país, e ainda combatia os estereótipos de inferioridade (BUTLER, 1998: 90-92).

\footnotetext{
${ }^{26}$ Contudo, em passagem a frente, na página 34, Fernandes afirma que o Grêmio Kosmos teria surgido junto a outras associações entre 1927 e 1945. Como já expusemos o Grêmio foi fundado em 1908. (FERNANDES, 1965)
} 
A pesquisa de Kim Butler, além sinalizar o nacionalismo como estratégia fundamental, infere à produção jornalística paulista um diálogo com os pares de jornais negros internacionais. Posteriormente, historiadores como Amilcar Araújo Pereira, Petrônio Domingues, Tiago de Melo Gomes e Flávio Thales Francisco Ribeiro confirmaram a hipótese e, demonstraram que houve um vínculo consolidado entre o periódico Clarim da Alvorada e a folha Chicago Defender, liderada por Robert Abbott (DOMINGUES, 2006; GOMES, 2007; RIBEIRO, 2010). A leitura de artigos da imprensa negra em jornais anteriores ao Clarim demonstrou, contudo, que também os líderes do movimento negro precedente, como Frederico Baptista de Souza e seu amigo Abílio Rodrigues, não apenas tinham ciência dos argumentos de seus pares norte-americanos, como faziam valer suas próprias percepções acerca do que era e como operava o racismo brasileiro, conforme pude verificar em pesquisa monográfica (TIEDE, 2002). É interessante notar, dessa maneira, que a autonomia não diz respeito, obviamente, apenas aos aspectos financeiros e sociais dos sujeitos históricos, mas sim, evidentemente, a um modo genuíno de pensar e organizar o mundo no pós-abolição.

Kleber Amâncio também destacou a autodeterminação e a vontade própria de inserção social como fatores decisivos nas experiências de ex-escravos, libertos e seus descendentes, em Campinas. $\mathrm{O}$ historiador aponta que as investigações que se restringem a compreender a opressão fazem denúncia do racismo e do preconceito, mas acabam impingindo certo silêncio aos oprimidos, que passam a serem entendidos como "não sujeitos". Assim, baliza que é necessário buscar por meio de documentos indiretos, ou seja, que não foram criados especificamente para registrar a experiência das pessoas comuns, o protagonismo de suas próprias vidas, porque é isso que, de fato, dará cidadania não fictícia às existências constituídas por sob o signo da escravidão. Entre as inovações que o autor apresenta sobre a interpretação da imprensa negra chama a atenção à análise do papel da "educação moral". Segundo o autor, a promoção da instrução pretendia o alcance da respeitabilidade social, e, portanto, dava aos sujeitos o protagonismo das ações, do mesmo modo que ocorrera com seus antepassados que tiveram papel crucial na luta pela abolição (AMÂNCIO, $2013: 22,68$ ).

A tese de Ana Flávia Magalhães Pinto se debruça especialmente sobre o curso de homens intelectuais negros que, em fins do século dezenove, circularam em São Paulo e no Rio de Janeiro. A pesquisa também amplia os horizontes de investigação sobre o período e tece um grande bordado entre as linhas que esses sujeitos vivenciaram em uma espacialidade compartilhada. É um trabalho que proporciona o reconhecimento dos 
indivíduos em seus locais sociais, bem como, as ausências intencionais ou ingênuas de seus nomes nos anais de instituições de poder, como a Faculdade de Direito. Além da conquista dessas biografias, Pinto se esmerou na reconstrução de um cenário político e social que abre caminhos possíveis de pesquisa; seu estudo já aponta para as relações entre a imprensa negra e abolicionista do século dezenove e os jornais negros do século vinte, hipótese que compartilho, e que requer mais investigação (PINTO, 2014).

Como sugeriu a historiadora, é provável que muitas redes de solidariedade tenham sido formadas em fins do século dezenove. As experiências em organizações religiosas e leigas, mutualistas e trabalhistas, partidárias e beneficentes, como já foi dito, podem amplificar a perspectiva de análise historiográfica sobre os militantes que lutaram em várias frentes diferentes para apoderar-se o que lhes era de direito, ou seja, o respeito da sociedade do pós-emancipação (GOMES, 2005; PINTO, 2010).

As redes de ajuda mútua foram o principal meio de solidariedade para os pobres em geral, em especial para aqueles que, além das adversidades econômicas, enfrentavam o desprezo social oriundo do racismo. Mas, sobretudo, para os que moravam no interior do estado e para os sujeitos que se encaminhavam para a capital, assim, ocorria a articulação de auxílios mútuos entre familiares e amigos com vistas a facilitar o pleito por moradia e trabalho. Algumas vezes, a proteção de famílias poderosas facilitava esse acesso a melhores condições de vida. Em outras, o vínculo se estabelecia junto a imigrantes pobres que habitavam os mesmos espaços (RIBEIRO, 2016).

Os processos de apagamento histórico que a população negra passa a padecer no início do século vinte são importantes, como já foi demonstrado pela historiografia brasileira. Contudo, partilho da ideia de Kleber Amâncio de que apenas apresentá-los não basta. Em alguma medida, a exibição do racismo por si só não introduz, como em um processo lógico, as dimensões das lutas e resistências impetradas contra esse tipo de discriminação (THOMPSON, 1987). Desse modo, é necessário dar ênfase aos processos de edificação e de reconstrução que os sujeitos históricos insistentemente mantiveram. Desse modo será possível descortinar, por exemplo, as redes estabelecidas para além das relações com famílias poderosas, e entre solidariedades que podiam se articular entre a própria "raça", mas também por dentre as diferenças de classe social, cultural, religiosa, partidária... Ou, ainda, porque há de existir aqueles que, a despeito da sua condição preterida ou privilegiada, entendiam que a luta por equidade deve ser de todos, mulheres e homens, negros e brancos. A contribuição da pesquisa aqui exposta, portanto, se assegura não na obra individual de um sujeito excepcional: a força do combate de 
Frederico repousa justamente no âmbito coletivo de seus pleitos e, principalmente, de suas atitudes. Que por meio da trajetória do indivíduo, é possível iluminar as demandas políticas, sociais e até mesmo afetivas de muitas pessoas, e ainda contribuir para os debates centrais da historiografia dos movimentos associativos negros na primeira metade do século vinte.

\section{Fontes}

CHIBATA (1932). Nós somos Judas da raça, quem serão os Cristos? São Paulo. FOLHA DA MANHÃ (1930). Mahatma Gandhi. São Paulo.

O ALFINETE, órgão literário, crítico e recreativo dedicado aos homens de cor (19181919, 1921.) São Paulo.

O BALUARTE, órgão oficial do Centro Literário dos Homens de Cor (1904). Campinas.

O CLARIM e O CLARIM D' ALVORADA, (1924-1932, 1940). São Paulo.

O CORREIO PAULISTANO, (1919). São Paulo.

O ESTADO DE SÃO PAULO. (1904-1919). São Paulo.

O KOSMOS, órgão do Grêmio Dramático e Recreativo Kosmos (1922-1925). São Paulo.

O MENELICK, órgão mensal, noticioso, literário e crítico dedicado aos homens de cor. (1915-1916). São Paulo.

UNESP/CEDEM. Fundo Clóvis Moura. (1931) Livro de Atas Sociedade Cooperadora O Clarim Alvorada. Regimentos e Atas de Associações. (Arquivos Históricos do CMU) - 1931. São Paulo.

UNIVERSIDADE DE SÃO PAULO (1942). Pasta do Funcionário Frederico Baptista de Souza. (Seção de Arquivo e Museu) - 1942. São Paulo.

\section{Referências Bibliográficas}

ABREU, Martha (2000). O Império do Divino - Festas religiosas e cultura popular no Rio de Janeiro (1830-1900). Rio de Janeiro: Nova Fronteira.

ALBERTO, Paulina L (2011). Terms of inclusion: black intellectuals in twentieth-century Brazil. The University of North Carolina Press.

AMÂNCIO, Kleber Antônio de Oliveira (2013). Pós-abolição e quotidiano: ex-escravos, ex-libertos e seus descendentes em Campinas (1888-1926). São Paulo: Alameda.

ANDREWS, George Reid (1998). Negros e brancos em São Paulo. (1888-1988). (Trad. Magda Lopes) Bauru: EDUSC.

APPIAH, Kwame Anthony (2016). Identidades. Brasilio Sallum Júnior (org.) [et al.] São Paulo: Editora da Universidade de São Paulo.

AZEVEDO, Thales de (1996). As elites de cor numa cidade brasileira: um estudo de ascensão social e classes sociais e grupos de prestígio. 2 ed. Salvador: EDUFBA: EGBA.

BARBOSA, Márcio (1998). Frente Negra Brasileira: depoimentos/entrevistas e textos. (Org. Quilomboje), São Paulo: Quilomboje.

BUTLER, Kim (2000). Freedoms given, freedoms won: Afro-Brazilians in post-abolition São Paulo and Salvador. Library of Congress Catalog-in-Publication, 1998. Second paperback printing. 
CARDOSO, Paulino de Jesus Francisco (2012). A luta contra apatia: Estudo sobre a instituição do movimento negro antirracista na cidade de São Paulo (1915-1931). Itajaí: NEAB; Casa Aberta.

CARVALHO, G. L. DE (2009). A imprensa negra paulista entre 1915 e 1937: características, mudanças e permanências. São Paulo: Universidade de São Paulo Faculdade de Filosofia, Letras e Ciências Humanas Departamento de História Programa de Pós-Graduação em História Econômica.

CHAPEAUX, Pedro Dechamps (1963). El negro em el periodismo cubano em el siglo $X I X$. Havana: Ediciones Revolución.

CÔRTES, Giovana Xavier da Conceição (2012). “"Leitoras': Gênero, Raça, Imagem e Discurso em O Menelick (São Paulo, 1915-1916).” Afro-Ásia, no. 46. Centro de Estudos Afro-Orientais - Universidade Federal da Bahia: 163-91.

CUTI (org). José Correia Leite (1992). ... E disse o velho militante José Correia Leite... (organizador e textos Cuti). São Paulo: Secretaria Municipal da Cultura

DOMINGUES, Petrônio. (2008) Decifrando os segredos internos: a transição do trabalho escravo para o livre no Brasil. Revista Iberoamericana, v.8, n. 31, p.197-205.

DOMINGUES, Petrônio (2007). Movimento negro brasileiro: alguns apontamentos históricos. Tempo [online], vol.12, n.23, pp.100-122.

DOMINGUES, Petrônio (2006). A visita de um afro-americano ao paraíso racial. Revista de História, vol. 2, n. 155, 161-181.

DOMINGUES, Petrônio (2006). O "messias" negro? Arlindo Veiga dos Santos (19021978) "Viva a nova monarquia brasileira; Viva Dom Pedro III!". Varia História, Belo Horizonte, vol. 22, n. 36, p. 517-536.

DOMINGUES, Petrônio (2000). Uma História não contada: negros, racismo e trabalho no pós-abolição em São Paulo (1889-1930). Tese (Doutorado em História) Universidade de São Paulo, São Paulo.

ELLISON, Ralph Waldo (1952). Invisible Man. New York: Random House.

FERNANDES, Florestan (1965). A integração do negro na sociedade de classes. Volume II, (3 ${ }^{\text {a }}$ Ed.) São Paulo: Dominus; Editora da Universidade de São Paulo.

FERRARA, Mirian Nicolau (1986). Imprensa negra paulista (1915-1960). São Paulo: FFLCH - USP.

FERREIRA, Maria Claudia Cardoso (2005). Representações sociais e práticas políticas do movimento negro paulistano: as trajetórias de Correia Leite e Veiga dos Santos (1928-1937). Dissertação (Mestrado em História). Universidade Estadual do Rio de Janeiro, Rio de Janeiro.

FORTES, Alexandre \& MATTOS, Hebe (2015). Pós-abolição no Mundo Atlântico. Revista Brasileira de História, v. 35, n. 69.

GELER, Lea. (2010). Periódicos y periodistas afro porteños a fines del siglo XIX. In: Andares negros, caminos blancos: Afroporteños, Estado y Nación Argentina a fines del siglo XIX. Rosario: Pro historia Ediciones; TEIAA, pp. 27-53.

GOMES, Flávio dos Santos (2005). Negros e política. Rio de Janeiro: Zahar.

GOMES, Tiago de Melo (2007). Afro-Brasileiros e a Construção da ideia de Democracia Racial nos Anos 1920. LINHAS, Florianópolis, vol. 8, n. 1, jan. / jun.

HELLWIG. J. David (edited by) (1992). African-American Reflections on Brazil's paradise. Philadelphia: Temple University Press.

LONER, Beatriz (1999). Classe operária: mobilização e organização em Pelotas: 18881937. Tese (Doutorado em Sociologia) Universidade Federal do Rio Grande do Sul, Porto Alegre.

MACCORD, Marcelo (2012). Artífices da Cidadania: Mutualismo, Educação e Trabalho no Recife Oitocentista. Campinas: Editora da Unicamp. 
MACIEL, Cleber da Silva (1997). Discriminações raciais: negro em Campinas (18881926). 2 ed. Campinas, SP: CMU/Unicamp.

MULLER, Liane. (2013). As contas do meu rosário são balas de artilharia. Dissertação (Mestrado em História) Pontifícia Universidade Católica do Rio Grande do Sul, Porto Alegre.

PEREIRA, Amilcar Araújo (2010). O mundo negro: a constituição do movimento negro contemporâneo no Brasil (1970-1995). Tese (Doutorado em História) Universidade Federal Fluminense, Rio de Janeiro.

PEREIRA, A. C (2016). Associativismo negro na Primeira República: o Grêmio Dramático Recreativo e Literário Elite da Liberdade. In: Anais Eletrônicos $V$ Congresso Sergipano de História: Encontro Estadual de História, Sergipe: ANPUH.

PINTO, Ana Flávia Magalhães (2014). Fortes laços em linhas rotas: literatos negros, racismo e cidadania na segunda metade do século XIX. Tese (Doutorado em História) Universidade de Campinas, Campinas.

PINTO, Ana Flávia Magalhães (2002). Imprensa Negra no Brasil do século XIX. São Paulo: Selo Negro (Coleção Consciência e debate).

QUINTÃO, Antônia Aparecida (2002). Irmandades Negras: Outro espaço de luta e resistência (1870/1890), São Paulo: Annablume.

REGINALDO, Lucilene (2011). O Rosário dos Angolas: Irmandades de africanos e crioulos na Bahia Setecentista. São Paulo: Alameda.

RIBEIRO, Flávio Thales Francisco (2010). Fronteiras em definição: identidades negras e imagens dos Estados Unidos e da África no jornal O Clarim da Alvorada (19241932). Tese (Doutorado em História) Universidade de são Paulo, São Paulo.

RIBEIRO, Jonatas Roque (2016). Escritos da liberdade: trajetórias, sociabilidade e instrução no pós-abolição no sul-mineiro (188-1930). Dissertação (Mestrado em História) Universidade de Campinas, Campinas.

RIOS, Maria e MATTOS, Hebe Maria (2004). O pós-abolição como problema histórico: balanços e perspectivas, Topoi, v. 5, n. 8, pp. 170-198.

SILVA, Mário Augusto Medeiros da. (2012). Fazer história, fazer sentido: Associação Cultural do Negro (1954-1964). Lua Nova, n. 85, São Paulo, pp. 227-273.

SILVA, Mário Augusto Medeiros da. (2017). Rastros do Cisne Preto: Lino Guedes, um escritor negro pelos jornais (1913-1969). Estud. hist. (Rio J.). vol.30, n.62, pp.597622. ISSN 0103-2186.

SILVA, Mário Augusto Medeiros da; UNGARETTI Adda Alessandra Piva e CAPORRINO, Amanda Walter (2017). Parecer técnico GEI no. 272-2013 - Clubes Sociais Negros de São Paulo. Secretaria de Estado da Cultura de São Paulo, Centro de Documentação da Unidade de Preservação do Patrimônio Histórico, Processo Condephaat 01097/2011

TENÓRIO, Valquíria Pereira (2010). Baile do Carmo: Festa, movimento negro e política das identidades negras em Araraquara-SP. Tese (Doutorado em Sociologia). Universidade Federal de São Carlos, São Carlos.

THOMPSON, E. P. (1987) A formação da classe operária inglesa. I A árvore da Liberdade. Trad. Denise Bottman. Rio de Janeiro: Paz e Terra.

TIEDE, Lívia Maria. (2002) Imprensa negra: espaço de sociabilidade em São Paulo no início do século XX. Monografia (Graduação em História). Universidade de Campinas: Campinas.

TIEDE, Lívia Maria. (2006) Sob suspeita: negros, pretos e homens de cor em São Paulo no início do século XX. Dissertação (Mestrado em História). Universidade de Campinas, Campinas. 
TUTTLE, William M. (1970). Race Riot: Chicago in the Red Summer of 1919. University of Illinois Press.

Artigo recebido em 15 de abril de 2018.

Aprovado em 30 de maio de 2018.

DOI:10.12957/intellectus.2018.33687 